\title{
Estimated Uncertainty of Calculated Liquefied Natural Gas Density from a Comparison of NBS and Gaz de France Densimeter Test Facilities
}

\author{
M. Roncier, R. Philippe, J. Saint-Just, and F. Dewerdt \\ Gaz de France, B. P. 33, 93211, La Plaine Saint-Denis, France
}

and

\author{
J. D. Siegwarth and J. F. LaBrecque \\ National Bureau of Standards, Boulder, CO 80303 \\ Accepted: December 16, 1982
}

\begin{abstract}
Liquefied natural gas (LNG) densities can be measured directly but are usually determined indirectly in custody transfer measurement by using a density correlation based on temperature and composition measurements. An LNG densimeter test facility at the National Bureau of Standards uses an absolute densimeter based on the Archimedes principle, while a test facility at Gaz de France uses a correlation method based on measurement of composition and density. A comparison between these two test facilities using a portable version of the absolute densimeter provides an experimental estimate of the uncertainty of the indirect method of density measurement for the first time, on a large $(32 \mathrm{~L})$ sample. The two test facilities agree for pure methane to within about $0.02 \%$. For the LNG-like mixtures consisting of methane, ethane, propane, and nitrogen with the methane concentrations always higher than $86 \%$, the calculated density is within $0.25 \%$ of the directly measured density $95 \%$ of the time.
\end{abstract}

\section{Introduction}

The density of liquefied natural gas (LNG) is one of the quantities needed to establish the value of a quantity of LNG for custody transfer. Two methods are available to determine density: by calculation from correlations of density as a function of composition and temperature, and by direct measurement.

The calculational method is the one commonly used. The density is inferred from measurements of temperature and composition using correlations such as one of those developed during the LNG density

About the Authors: M. Roncier, R. Philippe, J. Saint-Just, and F. Dewerdt are with Gaz de France. J. D. Siegwarth and J. F. LaBrecque are with the NBS Center for Chemical Engineering. project at the National Bureau of Standards (NBS) [1]. ${ }^{1}$ These calculational methods are based on a series of density measurements of LNG pure components [2] and mixtures [1] done at NBS. The composition is determined by gas chromatographic analysis of vaporized LNG samples [3-5].

Direct density measurement is accomplished by measuring the effect of the liquid density on some physical property of the density measuring instrument or densimeter immersed in the liquid. This property might be a buoyancy, frequency, or capacitance. Ideally, no other property of the liquid, such as temperature or composition, will affect the density measurement.

\footnotetext{
' Figures in brackets indicate literature references at the end of this paper.
} 
Though direct density measurement is not now used for custody transfer measurement, the measurement simplicity and the concurrent promise of a greater accuracy have generated an interest in applying densimeters to LNG density measurement.

A number of commercially built densimeters are presently available. Some of these instruments are capable of making cryogenic density measurements. In fact, some were designed specifically for LNG service; however, those built for LNG service are not tested or calibrated in LNG. LNG calibrations, when provided for the densimeters, are extrapolated from measurements in liquid nitrogen and ambient temperature hydrocarbons.

Gaz de France (GDF) has built a facility to test and calibrate commercial densimeters for LNG service [6]. NBS, at the request of and with the support of the American gas industry [7], also built a test facility, the density reference system (DRS) [5,8-12].

Both test facilities are similar in that the densimeters are tested in nominally isothermal samples of pure methane and LNG-like mixtures. They differ in that the GDF apparatus uses a calculational method to determine the density of the test liquid, while NBS uses an absolute densimeter to determine density. The densimeter is absolute in that the density of the liquid is determined by the Archimedes method using a single crystal of silicon as the plummet. No calibration liquid is needed or used.

If densimeters are used in custody transfer measurement of density, calibration facilities will be required to maintain measurement accuracy. A means of intercomparing such calibration systems will be required. A portable version of the DRS densimeter has been built for this purpose [13]. This unit, the portable reference densimeter (PRD), has been used to intercompare the DRS and the Gaz de France facilities. This intercomparison of the two test facilities provides an opportunity to compare direct density measurement and the calculational method of density determination. The estimates of the systematic uncertainty of the two methods should overlap.

\section{The Calibration Systems}

\subsection{The Gaz de France System}

The Gaz de France system (GDFS) [6] has been used to test a number of commercial densimeters. It is essentially composed of a $32 \mathrm{~L}$ sample container, figure 1 , placed inside a vacuum insulated dewar. The temperature of this sample container is regulated by circulation of cold nitrogen gas around it. The vapor pressure in the sample container is kept approximately constant by a back pressure regulator. The sample temperature corresponds to the liquid-vapor equilibrium temperature at the control pressure. The temperature of the circulating nitrogen gas is regulated to correspond to the sample temperature to minimize evaporation of the sample. The sample liquid

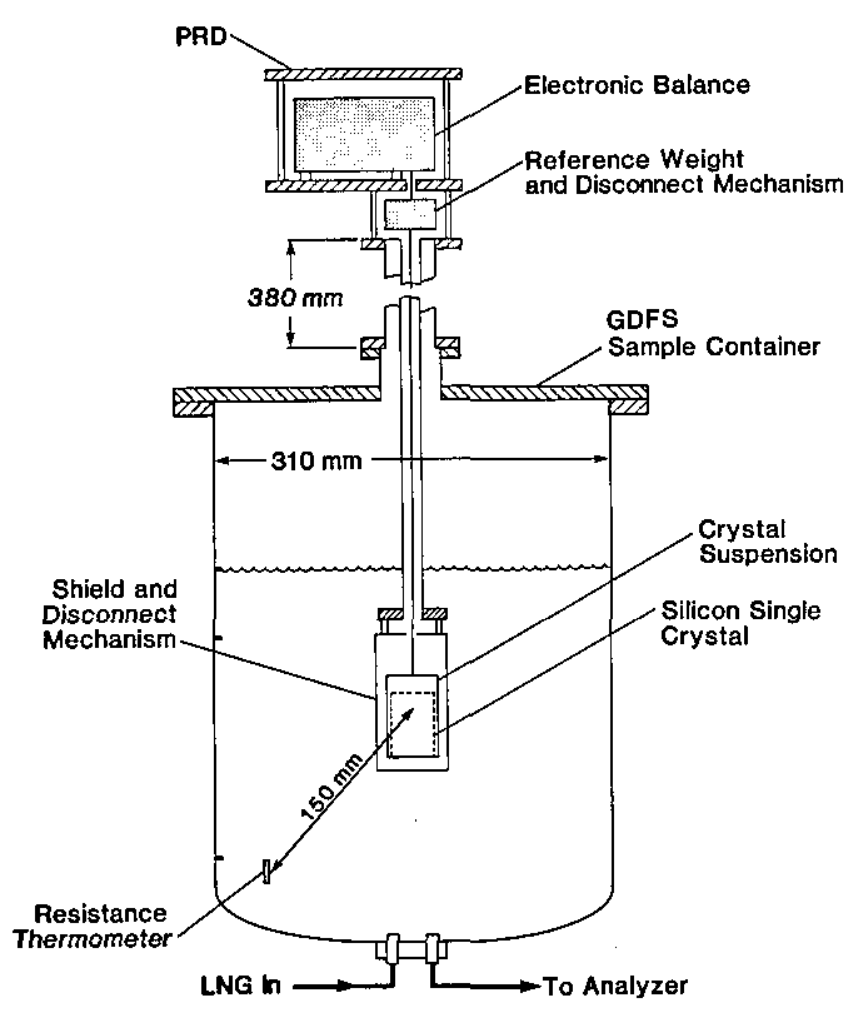

Figure 1-Schematic of the Gaz de France System sample container with the portable reference densimeter installed.

level is maintained at a sufficient height to immerse the densimeters tested. The level of liquid is maintained constant by injections of sample liquid. These injections also mix the sample.

The following parameters are measured:

1) The sample temperature, $T_{\mathrm{GDF}}$ is measured with the platinum resistance thermometer shown in figure 1. This thermometer is calibrated at a number of fixed points and its uncertainty is estimated to be $\pm 0.03{ }^{\circ} \mathrm{C}$.

2) The pressure in the vapor phase above the sample is also measured by a capacitance manometer. The uncertainty of this measurement is $\pm 0.25 \%$ of the full scale reading or \pm 12 mbar, whichever is larger.

3) A small quantity of the liquid sample is continuously vaporized and then analyzed by a 
gas chromatograph. The technique of sampling and chromatographic analysis has been discussed [3-6]. The uncertainty of the mole fractions of the constituents other than methane has been estimated as $\pm 1 \%$ of each fraction.

When a satisfactory liquid-vapor equilibrium is reached in the apparatus, the sample temperature, the vapor pressure, and the composition in the case of mixtures, are recorded at approximately 10-min intervals. Then, after changing the control pressure, possibly modifying the composition of the mixture, and injecting liquid until a new equilibrium is reached, a new set of data are recorded.

The sample density is calculated from the measurements of temperature, pressure, and composition of the sample. To determine the pure liquid methane density, only the temperature, $T_{\mathrm{GDF}}$ of the liquid near the bottom of the sample container is needed.

The density $\rho_{\mathrm{GDF}}$ for pure saturated liquid methane as a function of temperature is given by a correlation developed by Haynes and Hiza [2]:

$$
\rho-\rho_{\mathrm{c}}=\mathrm{a}\left(1-\frac{T}{T_{\mathrm{c}}}\right)^{0.35}+\mathrm{b}_{1}\left(1-\frac{T}{T_{\mathrm{c}}}\right)+\mathrm{b}_{2}\left(1-\frac{T}{T_{\mathrm{c}}}\right)^{4 / 3}
$$

where

$\rho=$ density in mol/ $/ \mathrm{L}$

$\rho_{\mathrm{c}}=10.16 \mathrm{~mol} / \mathrm{L}$ (critical density)

$T=$ methane temperature in $\mathrm{K}$

$T_{\mathrm{c}}=190.555 \mathrm{~K}$ (critical temperature)

$\mathrm{a}=18.65812 \mathrm{~b}_{1}=6.71203 \quad \mathrm{~b}_{2}=-0.947202 \mathrm{in} \mathrm{mol} / \mathrm{L}$.

To obtain the mass density values given in this report, $\rho$ must be multiplied by the molecular weight, $16.04303 \mathrm{~g} / \mathrm{mol}$.

The experimental apparatus was designed to obtain a good liquid-vapor equilibrium and ideally $T_{\mathrm{GDF}}$ and the temperature $T_{P}$ calculated from the vapor pressure using a parabolic interpolation of the pressuretemperature values in table 13 of reference [14] should agree. Since the sample chamber is not likely to be perfectly at equilibrium,

$$
\Delta T=T_{P}-T_{\mathrm{GDF}}
$$

can be used as a measure of the quality of the equilibrium within it. Part, if not all, of the $\Delta T$ can be a temperature gradient in the liquid.

From eq (1) and the two temperatures $T_{\mathrm{GDF}}$ and $T_{P}$, two values for the sample density can be calculated:
$\rho_{\mathrm{GDF}}=\rho\left(T_{\mathrm{GDF}}\right)$ and $\rho_{P}=\rho\left(T_{P}\right)$. The difference, $\delta \rho$, where $\delta \rho=\rho_{\mathrm{GDF}}-\rho_{P}$ provides an estimate of the measurement uncertainty of the density of pure methane. This estimated uncertainty, $\delta \rho / \rho$ is $\pm 0.15 \%$ assuming $\Delta T$ is entirely due to a liquid temperature gradient.

The density of a mixture is calculated from measurements of $T_{\mathrm{GDF}}, P$, and from measurements of the composition by the liquid sampling and calculation methods discussed earlier. The corresponding states method $[1,15]$ with an estimated uncertainty of $\pm 0.1 \%$ was used for this calculation. The vapor pressure and composition are used to calculate a sample temperature [16] as in the case of methane. This temperature is used along with the composition to calculate a second density value by the corresponding states method. This second density value again serves as an evaluation of the equilibrium.

This apparatus has been used to test a number of commercially built densimeters.

The uncertainty of the liquid methane density is discussed in Appendix A. The determination of LNG density from correlations of density with composition and temperature is subject to a number of sources of error. The estimated uncertainty of the mathematical models for predicting LNG density is $0.1 \%$ [1]. The composition determination is subject to uncertainty of the composition of the chromatograph calibration gas, the uncertainty of the chromatograph measurement, and the uncertainty introduced by the sampling procedure. The uncertainty of the temperature measurement must also be included. The uncertainties associated with the various parameters are as follows:

1) The uncertainty assigned to the sampling has been estimated to be 0.1 to $0.15 \%$ from tests of the sampling system [6].

2) The gas chromatograph used for the composition analysis is a state-of-the-art instrument. The uncertainty it introduces into a density determination will be dependent on the composition of the sample and the accuracy of the calibration gas. The uncertainty that the chromatographic measurement contributes to the density determination has been estimated in one study to be $0.11 \%$ for LNG [17]. Parrish et al. [3] estimated an uncertainty contribution of $0.1 \%$ by the chromatograph to the heating value calculation. The uncertainty introduced into the density calculation is generally equal to or slightly less than the heating value uncertainty.

3) Errors introduced by the calibration gas uncertainty are based on estimates of the weighing uncertainties when the standard is 
prepared and is probably no more than $\pm 0.03 \%$ [3]. An estimate for uncertainty introduced by deviations of the constituent gases is not available.

4) The density uncertainty introduced by the temperature measurement is about $\pm 0.01 \%$ for $\pm 30 \mathrm{mK}$ temperature uncertainty.

Parrish et al. [5] estimated that in the laboratory, the saturated density based on composition determinations from sampling and analysis combined with temperature and pressure measurement could be calculated to an uncertainty of $0.1 \%$. This value seems optimistic since combining the uncertainties above in quadrature gives the uncertainty of a laboratory determination of density calculated from temperature and composition measurements of at least $0.2 \%$. This includes no estimate of the uncertainty of the calibration mixture for the chromatograph other than that introduced by weighing the mixture.

\subsection{The Density Reference System (NBS)}

The NBS densimeter test facility, the density reference system (DRS), has been described in the literature $[5,8,9,11,12]$. It is a vacuum insulated sample container into which $16 \mathrm{~L}$ of methane or LNG-like mixtures can be condensed. The system is completely closed. No gas vents at anytime. Radiation shields cooled by liquid nitrogen reduce the heat leak into the sample container, and cooling coils remove the remainder. The liquid can be stirred by a turbine pump. The thermal isolation of the sample maintains the isothermal state for minutes after the stirring has ceased. The density of the sample liquid is measured by an absolute densimeter. This densimeter uses the Archimedes principle, a silicon single crystal immersed in the liquid is weighed by an electronic balance. The density of single crystal silicon is known to a few ppm, and if the vacuum weight of the crystal is measured, no calibrating fluid is necessary. The density of the liquid, $\rho_{l}$, is

$$
\rho_{l}=\rho_{\mathrm{s}}\left(1-M / M_{\mathrm{s}}\right)
$$

where $\rho_{\mathrm{s}}$ is the crystal density, $M_{\mathrm{s}}$ is its vacuum weight, and $M$ is its apparent weight when completely immersed in the liquid.

When commercial densimeters were found to lack adequate calibrations, a transfer standards program was initiated by NBS to provide a better method of calibration to manufacturers and users. Densimeters of a manufacturer's or user's choice were calibrated in the DRS, then returned to them. They would then use these calibrated instruments in their own sample container to calibrate densimeters sold. The calibration should be done in an LNG-like mixture for best results.

The transfer standard method of providing calibrations has disadvantages, however. The calibration of a standard could change with time or through shipping and handling. Repeated calibrations are necessary at least until a long term stability is established for the instrument. If the long term stability is adequate there still remains the question of how well the calibration system, in which the transfer standard is employed, transfers the calibration from the standard to the densimeter under calibration. Testing calibrated densimeters in the DRS or GDFS could establish whether the calibration has been adequately transferred. Continual monitoring of the calibration operation is desirable to ensure the best calibration of the commercially available densimeters.

During the course of testing the commercial densimeters, both the DRS and the DRS densimeter were improved. The densimeter was improved by replacing the original electronic balance with one of greater range, which was also more compact and more rugged. The greater range permits the silicon crystal to be weighed directly instead of in relation to a reference weight. The reference weight is retained in the new densimeter but now provides a means of adjusting and monitoring the balance calibration. This redesign suggested the possibility of making a portable standard densimeter of a design similar to the new DRS densimeter. This portable standard could be transported to other calibration facilities to measure their calibration uncertainty and to intercompare calibration facilities. A portable standard, the portable reference densimeter (PRD), has been built for this purpose. The PRD is shown schematically in figure 1 in place in the GDFS. This densimeter and comparison density measurements between it and the DRS are described in [12] and [13]. The densities of methane and methane-propane-nitrogen mixtures from simultaneous measurements by the PRD and the DRS densimeter were indistinguishable. Because of the larger crystal and the tungsten reference weight, the PRD is estimated to be slightly more accurate than the DRS densimeter. The density of pure methane liquid measured by the PRD is estimated to be within $\pm 0.033 \%$ of the true density $99.7 \%$ of the time.

One densimeter user built a calibration system with a densimeter of a similar design for his standard. This unit, tested also in the DRS [9], gave densities that agreed with the DRS values to better than $0.005 \%$ $\pm 0.01 \%$, supporting the contention that the DRS densimeter is an accurate, well characterized calibration instrument. 


\section{Intercomparison of GDFS and DRS}

The two test facilities were compared via the PRD. The PRD was air freighted from Boulder, CO, to the Centre de Recherches Gazieres of Gaz de France, located at St. Denis, near Paris, where it was inserted into the Gaz de France system. Densities of pure liquid methane samples and some mixtures were measured simultaneously with the PRD and the GDFS. These measurements are the first experimental comparisons between LNG-like mixture densities from correlations and from direct density measurement with an absolute densimeter.

Upon arrival in Paris, the PRD balance was out of calibration by the amount expected because of the difference in the acceleration of gravity between Boulder and Paris. The balance was recalibrated with the reference weight, installed in the GDFS, and some initial data were taken with assistance from an NBS representative. The rest of the measurements and the calculations were done by Gaz de France personnel.

\section{Results}

\subsection{Pure Methane}

The pure methane data were taken at two separate periods of time. Measurements were made at seven different values of sample vapor pressure; hence, temperature. Table 1 gives a summary of these measurements. The values shown are averages of a series of measurements at the conditions. The pressure in the first column was nominally constant during the set of measurements at that pressure. The thermometer measured an average $\bar{T}_{\mathrm{GDF}}$ during the same set of measurements and $\bar{\rho}_{\mathrm{GDF}}$ and $\bar{\rho}_{\mathrm{NBS}}$ are the averages of the densities measured by the GDFS and PRD, respectively. The average, $\overline{\Delta \rho / \rho}$ where

Table 1. Pure methane data.

\begin{tabular}{|c|c|c|c|c|c|c|}
\hline $\begin{array}{c}\bar{P} \\
\text { (mbar) }\end{array}$ & $\begin{array}{l}\bar{T}_{\mathrm{GDF}} \\
\left({ }^{\circ} \mathrm{C}\right)\end{array}$ & $\begin{array}{l}\bar{\rho}_{\mathrm{GDF}} \\
\mathrm{kg} / \mathrm{m}^{3}\end{array}$ & $\begin{array}{l}\bar{\rho}_{\mathrm{NBS}} \\
\mathrm{kg} / \mathrm{m}^{3}\end{array}$ & $\begin{array}{r}\overline{\Delta \rho / \rho} \\
(\%)\end{array}$ & $\begin{array}{c}\sigma(\Delta \rho / \rho) \\
(\%)\end{array}$ & $\begin{array}{c}\text { Number } \\
\text { of } \\
\text { observations }\end{array}$ \\
\hline 1018 & -161.39 & 422.59 & 422.08 & 0.121 & 0.005 & 18 \\
\hline 1038 & -161.25 & 422.38 & 421.83 & 0.131 & 0.015 & 17 \\
\hline 1514 & -156.37 & 415.14 & 414.62 & 0.124 & 0.034 & 13 \\
\hline 2009 & -152.50 & 409.02 & 408.75 & 0.066 & 0.021 & 25 \\
\hline 2435 & -149.49 & 404.77 & 404.36 & 0.102 & 0.006 & 21 \\
\hline 2960 & -146.59 & 399.92 & 399.52 & 0.101 & 0.010 & 14 \\
\hline 3092 & -145.81 & 398.66 & 398.39 & 0.069 & 0.002 & 6 \\
\hline
\end{tabular}

$$
\overline{\Delta \rho / \rho}={\overline{\left(\rho_{\mathrm{GDF}}\right.}}_{\left.-\bar{\rho}_{\mathrm{NBS}}\right) / \bar{\rho}_{\mathrm{NBS}}}
$$

is given in $\%$ in the fifth column and the standard deviation of $\Delta \rho / \rho$ is shown in the last column.

The value of $\Delta T$ from eq (2) varied during each set of measurements at a nominal temperature. In figure 2, $\Delta \rho$ is shown as a function of $\Delta T$. Some density gradient in the sample is apparent from these results

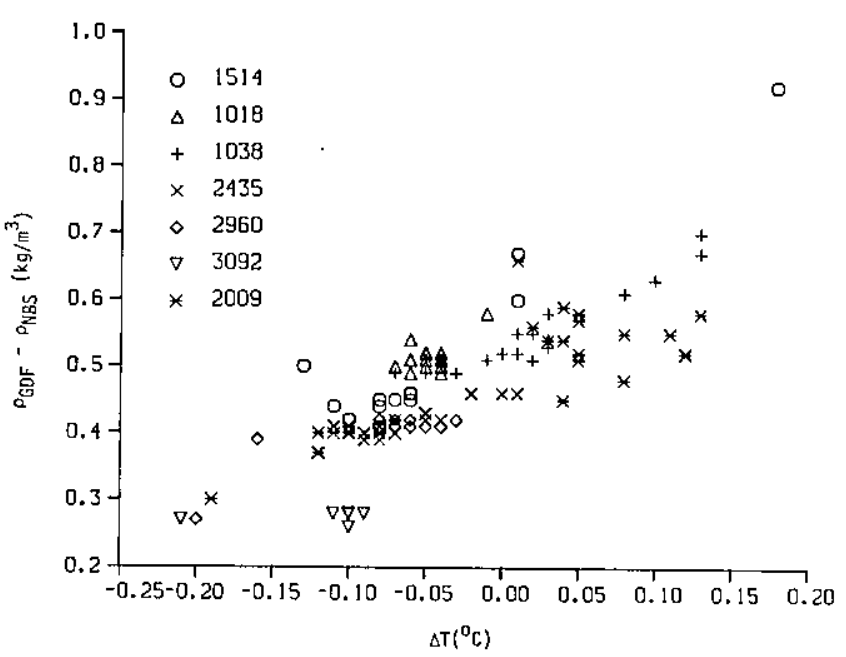

Figure 2-Difference between $\rho_{\mathrm{GDF}}$ (GDFS) and $\rho_{\mathrm{NBS}}$ (PRD) as a function of the $\Delta T$ of the sample container for pure methane. Each symbol corresponds to a set of measurements producing one line in table 1. The sample pressure in millibars is given adjacent to the various data symbols in the upper left corner.

since $\Delta \rho$ increases with $\Delta T$. To remove this effect, the $\Delta T$ dependence shown was fit by the method of linear least squares to obtain

$$
\Delta \rho=0.51+1.093 \Delta T\left(\mathrm{~kg} / \mathrm{m}^{3}\right) .
$$

The first term in eq (4) amounts to a constant offset of $0.51 \mathrm{~kg} / \mathrm{m}^{3}$, which is about $0.12 \%$ at a density of 425 $\mathrm{kg} / \mathrm{m}^{3}$. A similar offset $(0.10 \%)$ is observed at Boulder when the DRS densimeter density value was compared to the density value calculated from the average temperature of a saturated liquid methane sample using eq (1). The close agreement of the magnitude of these two offsets supports the contention that this indirect method gives densities about $0.1 \%$ higher than the direct method as used in the DRS. The Boulder comparisons between the direct and indirect density values gives a $99 \%$ upper bound on the standard deviation of a single measurement to be $0.046 \mathrm{~kg} / \mathrm{m}^{3}$. This includes variation within a test on a sample and variation between samples. For the Gaz de France data on the seven different samples, the variation between tests is estimated to have a standard 
deviation of $0.044 \mathrm{~kg} / \mathrm{m}^{3}$ with an upper $99 \%$ confidence limit of $0.115 \mathrm{~kg} / \mathrm{m}^{3}$ when the measured data is referenced to eq (4). The variation within tests has an estimated standard deviation of $0.041 \mathrm{~kg} / \mathrm{m}^{3}$ (114 observations in seven tests) with an upper $99 \%$ confidence limit of $0.048 \mathrm{~kg} / \mathrm{m}^{3}$. The upper $99 \%$ confidence limit for a single observation is then

$$
\left[(0.115)^{2}+(0.048)^{2}\right]^{1 / 2} \mathrm{~kg} / \mathrm{m}^{3}=0.125 \mathrm{~kg} / \mathrm{m}^{3}
$$

\subsection{Mixtures}

Table 2 shows the averaged compositions of each of the mixtures used in these comparisons along with the averaged values of $P, T_{\mathrm{GDF}}, \rho_{\mathrm{GDF}}, \rho_{\mathrm{NBS}}, \Delta \rho / \rho$, and $\sigma(\Delta \rho / \rho)$. The compositions shown are the average over a set of determinations at a particular composition and vapor pressure setting. The mixtures in table 2 are listed in the order the data were taken. The individual values of $\Delta \rho$ are shown as a function of the same order in figure 3 . The gap in the data shown was some pure methane measurements. Two methane samples were also measured prior to the start of the mixture data acquisition.

The standard deviations about the mean of a set of measurements on a binary mixture are estimated to be $0.15 \mathrm{~kg} / \mathrm{m}^{3}$. This will be called the within test standard deviation and it is judged the same for all 10 tests of the binary mixtures. The means themselves vary much more than the within test variability allows. The means have a standard deviation of $0.35 \mathrm{~kg} / \mathrm{m}^{3}$. We infer from this that circumstances are changing significantly from test to test. Part of the change in circumstances is the composition, but a large shift does occur between two tests of the same mixture; i.e., 0.7 $\mathrm{kg} / \mathrm{m}^{3}$ between the first two tests shown in figure 3 . These shifts in the means are larger than those observed for the pure methane data.

Equilibrium between the vapor phase and the liquid phase for mixtures is not easily obtained and probably accounts for the larger values for $\Delta T$ than observed for pure methane. The values of $\Delta T$ for the 10 binary mixtures had ranges from 0.1 to $0.4^{\circ} \mathrm{C}$. Correlations between $\Delta \rho$ and $\Delta T$ for any of these 10 tests were of no practical significance in explaining the scatter of

Table 2. Mixture data.

Averages of the data at each mixture and vapor pressure.

The balance of the composition of each mixture is methane.

\begin{tabular}{|c|c|c|c|c|c|c|c|c|c|}
\hline \multirow[b]{2}{*}{$\#$} & \multirow[b]{2}{*}{$\begin{array}{c}\bar{P} \\
(\mathrm{mbar})\end{array}$} & \multirow[b]{2}{*}{$\begin{array}{l}\bar{T}_{\mathrm{GDF}} \\
\left({ }^{\circ} \mathrm{C}\right)\end{array}$} & \multicolumn{2}{|c|}{$\begin{array}{r}\text { Composition } \\
\text { (balance, } \mathrm{CH}_{4} \text { ) }\end{array}$} & \multicolumn{2}{|c|}{$\begin{array}{l}\text { Average } \\
\text { densities }\end{array}$} & \multirow{2}{*}{$\begin{array}{r}\begin{array}{r}\text { Average } \\
\text { difference }\end{array} \\
\begin{array}{r}\overline{\Delta \rho / \rho} \\
(\%)\end{array}\end{array}$} & \multicolumn{2}{|c|}{$\begin{array}{l}\text { S.D. of } \\
\text { average } \\
\text { difference }\end{array}$} \\
\hline & & & $\begin{array}{l}\bar{X}_{\mathrm{C} 2 \mathrm{H} 6} \\
(\mathrm{~mol} \%)\end{array}$ & $\begin{array}{l}\bar{X}_{\mathrm{C} 3 \mathrm{H} 8} \\
(\mathrm{~mol} \mathrm{\% )}\end{array}$ & $\begin{array}{l}\vec{\rho}_{\mathrm{GDF}} \\
\left(\mathrm{kg} / \mathrm{m}^{3}\right)\end{array}$ & $\begin{array}{l}\vec{\rho}_{\mathrm{NBS}} \\
\mathrm{kg} / \mathrm{m}^{3}\end{array}$ & & $\begin{array}{c}\sigma(\Delta \rho / \rho) \\
(\%)\end{array}$ & $\begin{array}{l}\text { \# of } \\
\text { data } \\
\text { points }\end{array}$ \\
\hline 1 & 1460 & -156.40 & 4.13 & 0.00 & 427.81 & 427.61 & 0.044 & 0.044 & 10 \\
\hline 2 & 1378 & -157.22 & 3.87 & 0.00 & 427.92 & 427.04 & 0.207 & 0.030 & 23 \\
\hline 3 & 1446 & -156.30 & 3.43 & 1.32 & 432.32 & 433.01 & -0.153 & 0.144 & 16 \\
\hline 4 & 1494 & -155.75 & 5.45 & 1.31 & 437.31 & 437.10 & 0.048 & 0.123 & 13 \\
\hline 5 & 1237 & -158.54 & 4.45 & 1.12 & 437.63 & 437.76 & -0.030 & 0.213 & 6 \\
\hline 6 & 1330 & -157.52 & 3.94 & 1.01 & 433.87 & 434.04 & -0.038 & 0.099 & 16 \\
\hline 7 & 1356 & -161.14 & $3.62^{*}$ & $0.94^{*}$ & 440.73 & 440.14 & 0.132 & 0.015 & 16 \\
\hline 8 & 1930 & -152.67 & 4.25 & 0.00 & 422.41 & 421.99 & 0.101 & 0.053 & 14 \\
\hline 9 & 2390 & -149.10 & 4.71 & 0.00 & 418.46 & 418.58 & 0.055 & 0.032 & 16 \\
\hline 10 & 3034 & -145.36 & 4.55 & 0.00 & 412.15 & 412.06 & 0.018 & 0.024 & 12 \\
\hline 11 & 3026 & -144.99 & 6.98 & 0.00 & 418.85 & 418.83 & 0.003 & 0.028 & 12 \\
\hline 12 & 2992 & -145.01 & 8.00 & 0.00 & 421.91 & 421.83 & 0.020 & 0.047 & 4 \\
\hline 13 & 2970 & -145.12 & 8.29 & 0.00 & 423.00 & 422.94 & 0.002 & 0.099 & 18 \\
\hline 14 & 2454 & -148.24 & 7.60 & 0.00 & 425.66 & 425.60 & 0.014 & 0.032 & 10 \\
\hline 15 & 2040 & -150.17 & 12.63 & 0.03 & 442.99 & 443.39 & -0.090 & 0.120 & 12 \\
\hline 16 & 1980 & -150.72 & 13.00 & 0.03 & 444.83 & 445.18 & -0.078 & 0.027 & 11 \\
\hline 17 & 1491 & -156.55 & 0.00 & 2.85 & 430.61 & 430.54 & 0.025 & 0.131 & 16 \\
\hline 18 & 1958 & -153.06 & 0.00 & 2.91 & 425.83 & 426.14 & -0.071 & 0.023 & 12 \\
\hline
\end{tabular}

"plus $1.09 \mathrm{~mol} \% \mathrm{N2}$ 


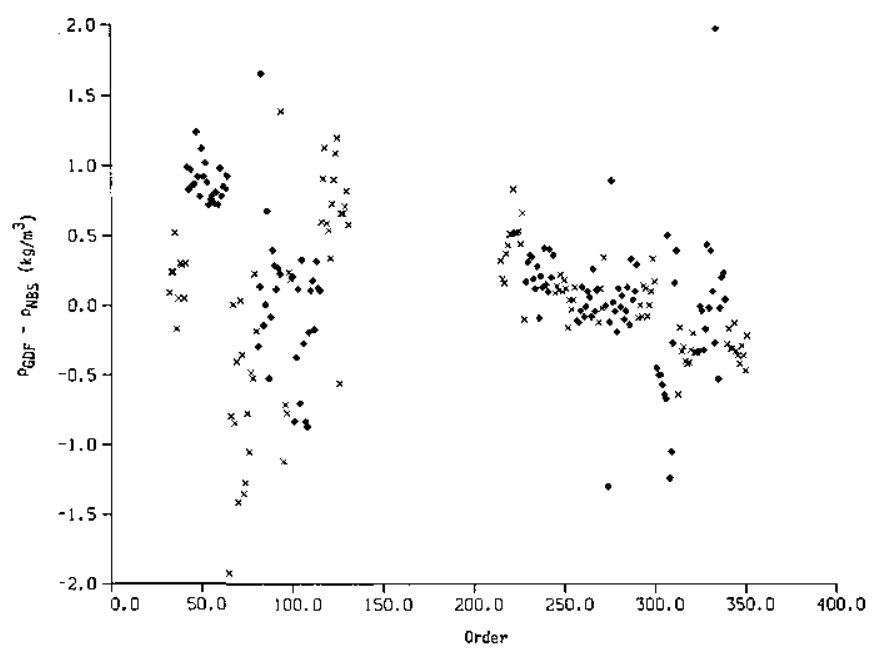

Figure 3-Differences in density measurements as a function of data order for the various mixtures. The mixtures changed where the symbols change and the compositions are given in table 2. Number 1 of table 2 is the first group of data on the left and number 8 is the first group after the gap. The gaps are the pure methane data.

the data. The scatter is probably due to the sampling and analysis procedures. Approximately $98 \%$ of the data fall within $\pm 0.18 \%$ of the overall mean.

The estimated standard deviations about the mean of a set of measurements of a ternary mixture are mostly around $0.5 \mathrm{~kg} / \mathrm{m}^{3}$. One is as low as $0.1 \mathrm{~kg} / \mathrm{m}^{3}$ and one as high as $0.9 \mathrm{~kg} / \mathrm{m}^{3}$. The eight means themselves are varying with an estimated standard deviation of $0.3 \mathrm{~kg} / \mathrm{m}^{3}$. Approximately $95 \%$ of this data fall within $\pm 0.25 \%$ of the overall mean.

\section{Conclusions}

Though the density determined from temperature and composition measurements using a correlation has been compared to the density measured by commercial densimeters [6], this work represents the first known comparison to an absolute densimeter. This comparison provides a direct experimental estimate of the uncertainty associated with the method of determining density from correlations using measured temperature and composition.

The density measured by the PRD in pure liquid methane was $0.12 \%$ smaller than the density determined by the GDFS by calculation from a sample temperature measurement provided a correction is introduced for $\Delta T$. Similar results were obtained in the DRS. When the directly measured liquid methane density is compared to the density calculated from the averaged readings of two thermometers, the directly measured density is $0.10 \%$ low. This means that the GDFS and the DRS agree to within $0.02 \%$ on density measurements in pure methane when a correction is made for the $0.1 \%$ offset between direct density measurement by the DRS or PRD and the Haynes-Hiza density from temperature correlation [2]. Thus, the two test systems show good agreement on liquid methane density. The upper $99 \%$ limit of a measurement of density in this comparison is $0.125 \mathrm{~kg} / \mathrm{m}^{3}$ compared to a similar limit of 0.046 $\mathrm{kg} / \mathrm{m}^{3}$ for the DRS [9].

The densities of the mixtures examined in this work measured by the GDFS and the PRD differed by no more than $0.25 \%$ in $95 \%$ of the measurements. This value does not conflict with the estimated errors for the two measurement methods but is larger than the $0.1 \%$ estimated from the heating value studies [5]. The uncertainty in heating value was estimated to be $\pm 0.15 \%$ in the laboratory [5] and $\pm 0.3 \%$ for measurements on shipboard [3]. Based on this, the uncertainty in field measurement of LNG density by sampling and analysis of the liquid could be larger than the $\pm 0.25 \%$ obtained in the comparison of the DRS and GDFS described in this paper.

\section{References}

[1] McCarty, R. D. Four mathematical models for prediction of LNG densities. Natl. Bur. Stand. (U.S.) Tech. Note 1030 (December 1980). Also, McCarty, R. D. Mathematical models for the prediction of liquefied natural gas densities, J. Chem. Thermodynamics 14, 837 (1982).

[2] Haynes, W. M.; Hiza, M. J. Measurements of orthobaric liquid densities of methane, ethane, propane isobutane and normal butane, J. Chem. Thermodynamics 9, 179 (1977).

[3] Parrish, W. R.; Arvidson, J. M.; LaBrecque, J. F. Development and evaluation of an LNG sampling measurement system, Natl. Bur. Stand. (U.S.) NBSIR 78887 (July 1978).

[4] Parrish, W. R.; Arvidson, J. M.; LaBrecque, J. F. Evaluation of LNG sampling measurement systems for custody transfer, AGA Operating Section Proceedings, Proceedings of the Transmission Conference; Montreal, Quebec; T-236 (1978).

[5] Parrish, W. R.; Brennan, J. A.; Siegwarth, J. D. LNG custody transfer research at the National Bureau of Standards, AGA Operating Section Proceedings; Proceedings of the Transmission Conference, Montreal, Quebec, Canada; T.243 (1978).

[6] Dewerdt, F.; Mousset, P. Contribution à l'amélioration du comptage du GNL-Evaluation de densimètres et échantillonneurs pour GNL, Sixth International Conference on Liquefied Natural Gas, Kyoto, Japan (1980); Appendix, Paper 8.

[7] The work was supported first by the American Gas Association and later by the Gas Research Institute. 
[8] Siegwarth, J. D.; Younglove, B. A.; LaBrecque, J. F. Cryogenic fluids density reference system: provisional accuracy statement, Natl. Bur. Stand. (U.S.) Tech. Note 698 (November 1977).

[9] Siegwarth, J. D.; LaBrecque, J. F. Cryogenic fluids density reference system: provisional accuracy statement (1980), Natl. Bur. Stand. (U.S.) Tech. Note 1041 (1981).

[10] Siegwarth, J. D.; Younglove, B. A.; LaBrecque, J. F. An evaluation of commercial densimeters for use in LNG, Natl. Bur. Stand. (U.S.) Tech. Note 697 (October 1977).

[11] Siegwarth, J. D.; LaBrecque, J. F.; Younglove, B. A. Test of densimeters for use in custody transfer of LNG, Proceedings 53rd International School of Hydrocarbon Measurement; Norman, Oklahoma (1978) p. 385.

[12] Siegwarth, J. D.; Brennan, J. A. LNG instrumentation for custody transfer, AGA Operating Section Proceedings; Proceedings of the Transmission Conference; Atlanta, Georgia; T-119 (1981).

[13] Siegwarth, J. D.; LaBrecque, J. F. A portable calibration densimeter for use in cryogenic liquids, Natl. Bur. Stand. (U.S.) Tech. Note 1035 (1981).

[14] Goodwin, R. D. The thermophysical properties of methane from 90 to $500 \mathrm{~K}$ at pressures to 700 bar, Natl. Bur. Stand. (U.S.) Tech. Note 653 (April 1974).

[15] McCarty, R. D. A comparison of mathematical models for the prediction of LNG densities, Natl. Bur. Stand. (U.S.) NBSIR 77-867 (October 1977).

[16] The method is described in an unpublished note by Gaz de France. The method is based on the work by Lee, B.; Erbar, J. H.; and Edminster, W. C., Prediction of thermodynamic properties for low temperature hydrocarbon process calculations, AIChE Journal 19, 349 (1973).

[17] Mann, D. B.; Diller, D. E.; Olien, N. A.; Hiza, M. J. Measurements of liquefied natural gas in commerce, AGA Operating Section Proceedings, Proceedings of the Distribution Conference; Washington, DC; D-206 (1973).

\section{Appendix A}

\section{Influence of Impurities in Methane}

The pure liquid methane was made by liquefying a compressed gas which had a certified methane content above $99.9 \%$. The impurities present may be distributed as follows (\% vol):

\begin{tabular}{|c|c|c|}
\hline - & & \\
\hline $\mathrm{O}_{2}$ & & ( \\
\hline $\mathrm{H}_{2} \mathrm{O}$ & & \\
\hline$\Delta$ & & \\
\hline $\mathbf{N}_{2}$ & & 0.0 \\
\hline $\mathrm{H}_{2}$ & & 000 \\
\hline & & 0.0 \\
\hline & & 0.0 \\
\hline
\end{tabular}

The chromatographic analysis is capable of detecting: the sum of $\mathrm{O}_{2}, A, \mathrm{~N}_{2} \geq 0.005 \%, \mathrm{C}_{2} \mathrm{H}_{6} \geq$ $0.01 \%, \mathrm{C}_{3} \mathrm{H}_{8} \geq 0.015 \%$, and $\mathrm{C}_{4} \mathrm{H}_{10} \geq 0.02 \%$.
The analysis was not done in a systematic way for the tests conducted with methane. The few occasional checks made did not reveal any impurities. The low solubility of $\mathrm{H}_{2}, \mathrm{O}_{2}, A, \mathrm{~N}_{2}$ in liquid methane and the method of filling the sample container involves a certain amount of evaporation and prevents any accumulation of these constituents.

On the other hand, $\mathrm{C}_{2} \mathrm{H}_{6}$ and the heavier hydrocarbons may accumulate during the course of measurement. Considering the capacity of the sample container, the volume of liquefied methane, the low evaporation rate and the experimental procedure, it was estimated that a maximum concentration of $0.1 \%$ of ethane was possible, leading to a systematic error of $0.12 \%$ for the density determination. However, no ethane was ever detected in an analysis, so it never exceeded $0.01 \%$ concentration. 